\title{
Parentesco civil em decorrência da técnica de reprodução assistida heteróloga
}

Civil kinship as a result of heterologous assisted reproduction

1 Mariana Nicolau Macedo Fidelis mari-macedo91@hotmail.com

1 Faculdade de Direito Professor Damásio de Jesus (FDDJ).

\section{RESUMO}

O presente estudo possui como objetivo destacar a mudança trazida pelo Código Civil de 2002, que proporcionou inédita abrangência ao conceito de parentesco civil através da inserção do conceito "outra origem", constante no artigo 1.593, em contraste com a predominância da técnica legislativa da casuística no Código Civil de 1916, que restringia seu alcance apenas à adoção, de forma taxativa. Ademais, será questionada a possibilidade do indivíduo concebido através de técnica de reprodução assistida heteróloga conhecer sua origem genética, e se tal conhecimento implica desfazimento do vínculo de parentesco civil anteriormente estabelecido, bem como se o conhecimento da ascendência biológica estabelece efeitos jurídicos compatíveis com a filiação.

\section{Palavras-chave}

Reprodução assistida heteróloga; parentesco civil; origem genética.

\begin{abstract}
This study aims to highlight the changes brought by the Civil Code of 2002, which provided unprecedented coverage to the concept of civil kinship, by inserting the concept "other source", contained in article 1.593, in contrast to the predominance of the legislative technique of casuistry in the Civil Code of 1916, which restricted its scope only to the adoption, Furthermore, it is questioned the possibility of the individual conceived through heterologous assisted reproduction technique to know their genetic origin, and if such knowledge entails the undoing the bond of legal parentage previously established, as well as if the knowledge of biological descent establishes legal effects compatible with parent-child relationship.
\end{abstract}

\section{Keywords}

Heterologous Assisted Reproduction; civil kinship; genetic background.

\section{Como você deve citar?}

FIDELIS, Mariana Nicolau Macedo. Parentesco civil em decorrência da técnica de reprodução assistida heteróloga. Cadernos UniFOA, Volta Redonda, n. 32, p. 79-88, dez., 2016. 


\section{INTRODUÇÃO}

Até poucas décadas, ao casal acometido por problemas de esterilidade e infertilidade no Brasil, bem como aos pares homoafetivos, solteiros que desejavam constituir família monoparental e indivíduos que desejavam instituir uns com os outros uma parceria de paternidade, o direito à reprodução só poderia se concretizar através do instituto da adoção.

Em meados da década de 1980, com o avanço científico no âmbito da ginecologia, obstetrícia e embriologia no Brasil, observou-se o emprego de variadas técnicas de reprodução assistida heteróloga, realizadas através de doação de material genético de um terceiro, de forma a não mais existir a limitação do vínculo de parentesco à verdade biológica, segundo Dias $(2015$, p. 378).

Por consequência, possibilitou-se maior eficácia ao exercício dos direitos reprodutivos, ainda que não se verifique transmissão de carga genética entre o pai socioafetivo (o cônjuge ou companheiro não doador) e a criança concebida através de técnica de reprodução assistida heteróloga.

O artigo 1.593 do Código Civil de 2002 possibilitou uma inovação no ordenamento jurídico, ao corresponder a expressão "outra origem" ao conceito de parentesco civil, que, durante a vigência do Código Civil de 1916, possuía uma abordagem taxativa ao restringir a possibilidade de se estabelecer parentesco civil apenas ao instituto jurídico da adoção, mediante a utilização da técnica legislativa da casuística.

Em que pese a mudança trazida pelo Código Civil de 2002, é possível observar alguns questionamentos não respondidos pelo ordenamento jurídico pátrio: é possível que o indivíduo oriundo de técnica de reprodução assistida heteróloga tenha o direito de conhecer sua identidade genética, em detrimento do direito à intimidade genética do doador? 0 conhecimento da origem genética ocasiona 0 desfazimento do vínculo de parentesco civil anteriormente estabelecido? Poderia o filho pleitear efeitos típicos advindos do estado de filiação em relação ao doador de material genético?

\section{DO PARENTESCO CIVIL}

As relações de parentesco foram submetidas a sensíveis mudanças ao longo dos séculos. Um longo caminho precisou ser percorrido, a fim de que as designações discriminatórias fossem abolidas pelo ordenamento jurídico, e que o vínculo afetivo fosse finalmente um fator determinante para o estabelecimento da filiação.

No Código Civil de 1916, o conceito de parentesco derivava da relação jurídica que vinculava entre si as pessoas que descendiam, diretamente, umas das outras, ou que derivavam de um mesmo tronco ancestral, e através do instituto da adoção. ${ }^{2}$

Após o advento da Constituição Federal de 1988, tornou-se evidente que o conceito clássico de parentesco não abrangia os preceitos do garantismo constitucional, além de não apresentar regulamentação viável às situações decorrentes do emprego das técnicas de reprodução assistida heteróloga e da presença crescente do afeto nas relações familiares.

22 Art. 332 do Código Civil de 1916 - o parentesco é legítimo, ou ilegítimo, segundo procede, ou não de casamento; natural, ou civil, conforme resultar de consanguinidade, ou adoção. 
Por consequência, o conceito de parentesco precisou ser submetido a necessárias e significativas alterações, a fim de que pudesse obter compatibilidade com os preceitos da Carta Maior, segundo Farias e Rosenvald.

O parentesco, desta maneira, tem de modelar a uma nova feição da família decorrente da normatividade garantista e solidária constitucional, abandonando a interconexão implicacional com o matrimônio e a feição hierarquizada e patriarcal para ser compreendido, em larga escala, como um vínculo predestinado a afirmação de valores constitucionais contemplados na tábua axiomática. (FARIAS; ROSENVALD, 2013, p.603).

Hodiernamente, consoante Gonçalves (2011, p. 310), o parentesco natural é resultante de vínculo biológico entre os indivíduos, ou seja, da consanguinidade, ao passo que o parentesco civil, por criação da lei, estabelece vínculo fundado em hipóteses, nas quais não há vínculo biológico presente.

No emprego das técnicas de reprodução assistida heteróloga, ou seja, mediante utilização de material genético de um terceiro, observa-se a superação do critério estritamente biológico na determinação das relações de parentesco, de maneira que a relação paterno-filial passou a encontrar na afetividade, do amor, e na busca da felicidade mútua, seus elementos basilares, independentemente da existência de vínculo biológico.

A substituição do elemento biológico pelo elemento afetivo determinou que a verdadeira paternidade não mais deriva do elemento genético. Com efeito, para Farias e Rosenvald (2013, p. 638), infere-se que "o avanço das técnicas de reprodução assistida e a possibilidade de participação de terceiros na determinação da filiação provocam um abalo sísmico nas bases da filiação".

Aduz Lôbo (2004, p. 527) registra que o estado de filiação já não se encontra intrinsecamente conectado ao vínculo biológico, e, atualmente, o estado de filiação de cada indivíduo é único e de natureza socioafetiva, afırmando-se na convivência familiar, consolidada na afetividade, já que a própria Constituição Federal de 1988 abrange o estado de filiação de qualquer natureza, seja socioafetiva ou biológica, sem primazia de um sobre o outro.

A técnica legislativa da casuística, amplamente utilizada na vigência do código Civil de 1916, caracterizava-se pela rigidez e imutabilidade, atribuindo-se alcance restritivo às normas. Como consequência, a referida técnica era acompanhada pela pretensão de completude (COSTA, 1998), ou seja, a intenção de apresentar imediatas soluções a todos os problemas apresentados pela realidade fática.

A pretensão de completude possibilitou, por consequência, a inadequação do Código Civil de 1916, especialmente no que se referia ao Direito das Famílias, caracterizado pela constante reconstrução de paradigmas, ao restringir o alcance e a eficácia de seus dispositivos a situações anteriormente previstas.

Mudanças econômicas e sociais evidenciaram a ineficácia presente no emprego exclusivo da técnica da casuística e privilegiaram o surgimento de normas, nas quais não há exata correlação entre a hipótese e suas consequências, mas a inserção de conceitos, cujos significados são intencionalmente vagos, e que recebem a denominação de "conceitos jurídicos indeterminados" (COSTA, 1998).

Na elaboração do Código Civil de 1916, não se vislumbrava a crescente intervenção humana no processo reprodutivo, e tampouco, a observância do fenômeno da desbiologização do parentesco (FARIAS; ROSENVALD, 2013, p.620).

Com o intuito de regulamentar as mais variadas situações existentes nas relações de parentesco não previstas pelo Código Civil de 1916, tais como a socioafetividade e o emprego das técnicas de reprodução assistida heteróloga, o texto final do artigo 1.593 do Código Civil de 2002 estabeleceu, in verbis: 
Art. 1593: O parentesco é natural ou civil, conforme se resulte de consanguinidade ou outra origem.

Mediante o disposto no artigo 1.593 do Código Civil de 2002, o parentesco civil resulta de "outra origem". A substituição do termo "adoção" por "outra origem" propiciou inédita abrangência ao conceito de parentesco civil, e, nesse contexto, a correspondência do termo "outra origem" ao conceito de parentesco civil deve ser vista como verdadeira cláusula geral de interpretação.

Preconiza Costa (1998) que as cláusulas gerais atuam como espécies de metanormas, cujo objetivo é fornecer ao magistrado critérios determináveis, que possam incluir, em uma mesma hipótese, uma variedade de casos, com características específicas que serão estabelecidas pela jurisprudência, não se olvidando, obviamente, da aplicação dos princípios constitucionais, em especial, do macroprincípio da dignidade da pessoa humana.

O Código Civil de 2002 é dotado de combinação entre as técnicas legislativas da casuística e das cláusulas gerais, com o intuito de conferir maior de certeza jurídica, cuja intensidade seria consideravelmente menor caso fossem utilizadas apenas cláusulas gerais, em detrimento da casuística.

Justamente, a inserção da cláusula geral de interpretação "outra origem" visa a abarcar as mais variadas situações existentes no Direito das Famílias não regulamentadas pela técnica da casuística, adotada pelo Código Civil de 1916. Nesse sentido, aduz Gama:

\begin{abstract}
O preceito contido no art. 1593 do Código Civil de 2002, corretamente interpretado, reconhece o parentesco decorrente da procriação assistida heteróloga expressamente no âmbito do Direito de Família. É importante ressaltar que tal espécie de parentesco civil sempre existiu, a despeito da falta de expressa previsão legislativa, e, nesse sentido, se mostra digna de importante nota a referência à outra origem para designar o parentesco civil. A mudança, apenas formal, da redação do art. 1.593 do Código Civil de 2002 permitirá confirmar, fundamentalmente, toda a construção teórica realizada para demonstrar a importância do reconhecimento de outra origem não sanguínea do parentesco que não apenas a adoção no sistema jurídico brasileiro. (GAMA, 2004, p.282).
\end{abstract}

No emprego das técnicas de reprodução assistida heteróloga, o vínculo de parentesco não será estabelecido entre a criança e o doador de material genético, que atuará como uma espécie de auxiliador na efetivação do direito à reprodução do casal. 0 parentesco natural se estabelecerá apenas em relação à mãe, ao passo que o parentesco civil se estabelecerá em relação ao marido ou convivente que expressou prévio consentimento para o emprego de técnica de reprodução assistida heteróloga.

Consoante Lôbo (2004, p.525), a convivência familiar e a afetividade entre a criança e seu pai socioafetivo, são, em primeiro instante, presumidas pelo legislador em casos de uso de técnica de reprodução assistida heteróloga e, posteriormente, consolidam o estado de filiação socioafetiva irrevogável.

\title{
3 DA REGULAMENTAÇÃO NORMATIVA
}

Para Venosa, (2009, p. 213) o "Código Civil não autoriza nem regulamenta a reprodução assistida, mas apenas constata lacunosamente a existência da problemática e procura dar solução ao aspecto da paternidade".

O Código Civil possui um único dispositivo legal, o artigo 1.597, oriundo de prévia emenda proposta no Senado Federal, que se refere especificamente às técnicas de reprodução assistida. Apesar da referência expressa, é possível constatar omissão normativa no que concerne aos aspectos civis relevantes (GAMA, 2004, p.266), e insuficiente atenção aos mecanismos que poderiam possibilitar o eficaz exercício do direito à reprodução. 
Com o intuito de regulamentar no campo deontológico as situações advindas do emprego das técnicas de reprodução assistida, com o intuito de estabelecer diretrizes de conduta às clínicas e médicos, foi elaborada pelo Conselho Federal de Medicina a Resolução n. 2121/2015, que, ao revogar a Resolução n. 2013/2013, autorizou o emprego das técnicas de reprodução assistida para relacionamentos homoafetivos, de indivíduos que desejam constituir família monoparental e da gestação compartilhada em união homoafetiva feminina, na qual não exista infertilidade.

Recentemente, o provimento de $n^{\circ} 42$ da Corregedoria Nacional de Justiça possibilitou o registro de crianças oriundas de técnicas de reprodução assistida independentemente de autorização judicial, de maneira a simplificar o aludido procedimento. ${ }^{3}$

Apesar da inovação trazida pela redação do artigo 1.593 do Código Civil de 2002, que proporcionou o estabelecimento de vínculo de parentesco civil entre a criança e seu pai socioafetivo, em casos de reprodução assistida heteróloga, a lacuna legislativa em relação à extensão do sigilo concedido ao doador de material genético proporciona inúmeros questionamentos jurídicos.

Gama (2004, p.283) acredita ser perfeitamente possível a aplicação da analogia entre a reprodução assistida heteróloga e a adoção, no que tange à solução dos conflitos, tendo em vista que ambos os institutos jurídicos possuem como base a "origem não sanguínea para fins de estabelecimento do parentesco civil."

Certamente, as posições doutrinárias tentarão abarcar as inúmeras situações advindas da reprodução assistida através do emprego da analogia com institutos jurídicos semelhantes, e da aplicação de variados princípios e regras constitucionais e infraconstitucionais. Por consequência, segundo Scalquette (2010, p.27), é propiciado o surgimento de uma verdadeira "colcha de retalhos", no que tange às alternativas apresentadas.

\section{INDAGAÇÕES ACERCA DO DOADOR DE MATERIAL GENÉTICO}

Não há de se negar a existência de vínculo biológico existente entre a criança e o doador de material genético. No entanto, em hipótese de emprego de técnica de reprodução assistida heteróloga, resta claro que o legislador consagrou maior importância à filiação não biológica, baseada no estado de filiação socioafetiva e na convivência familiar.

Por consequência, observa-se a aparente colisão entre dois direitos fundamentais: primeiramente, o direito à intimidade genética do doador, que visa a preservar o sigilo de seus dados genéticos, e o direito à origem genética do indivíduo concebido através de técnica de reprodução assistida heteróloga.

Por um lado, a intimidade genética constitui direito fundamental de quarta geração associado à privacidade e dignidade da pessoa humana (LOCATELI; PANDOLFO, 2014). Aduz Glancy (apud WARREN; BRANDEIS, 1979) registra que o direito à intimidade incorpora um viés psicológico, na medida em que a personalidade de um indivíduo, bem como sua autoimagem, podem sofrer danos em virtude de divulgação de informações ou dados pessoais a outras pessoas.

3 Art. 10 do provimento n. 42: 0 assento de nascimento dos filhos havidos por técnicas de reprodução assistida será inscrito no livro "A", independentemente de prévia observada a legislação em vigor, no que for pertinente, mediante o comparecimento de ambos os pais, seja o casal heteroafetivo ou homoafetivo, munidos da documentação exigida por este provimento. 
O direito à intimidade genética está atrelado a uma concepção que o indivíduo possui sobre si mesmo, ou seja, é parte de sua vida privada (LOCATELI; PANDOLFO, 2014). Em tese, os dados e informações genéticas individuais não poderão ser divulgados a terceiros sem a autorização do seu titular, até porque o progresso científico deve ser promovido em constante observância aos ditames do macroprincípio da dignidade da pessoa humana. ${ }^{4}$

Por força de proteção constitucional, prevista no art. $5^{\circ}, X$, da Constituição Federal de 1988, é inviolável a intimidade dos cidadãos, e, nesse contexto, é possível inserir a proteção à intimidade genética do doador, ou seja, ao seu padrão genético individual e único.

0 doador de material genético, consoante Diniz (2011, p. 623), "tem direito ao anonimato e ao não estabelecimento da paternidade biológica, e, de outro lado, reforçar-se-á a preservação da unidade familiar e da paternidade socioafetiva."

Por outro lado, o direito à intimidade genética assume caráter antagônico com o direito do indivíduo em conhecer a sua origem genética, que possui natureza de direito fundamental, na categoria de direito da personalidade (LÔBO, 2004, p. 523).

Em determinadas ocasiões, o filho advindo de técnica de reprodução assistida heteróloga deseja conhecer sua origem biológica com o intuito de satisfazer uma necessidade psicológica, sem almejar a ruptura de vínculo de parentesco civil existente com o pai socioafetivo.

Com efeito, a revelação da ascendência genética paterna, segundo Almeida (2004, p.428), contribui para o exercício inerente à condição de pessoa do indivíduo e a consequente formação de sua personalidade, mediante o conhecimento da identidade pessoal de seus ancestrais.

O conhecimento da origem genética possibilita que o indivíduo conheça sua ancestralidade, constituição genética individual e aspectos socioculturais, além de satisfazer um anseio natural do homem em conhecer suas origens (LÔBO, 2004, p. 524).

O conhecimento da origem genética encontra fundamento no direito à personalidade humana, ou seja, possui uma proteção constitucional, assim como o sigilo concedido ao doador, que se encontra embasado no direito à intimidade genética. Ambos os direitos são protegidos pelo macroprincípio da dignidade da pessoa humana, e, certamente, não há nenhuma hierarquia que conceda privilégios a cada um deles, de forma específica.

A resolução do aparente conflito entre os direitos fundamentais em questão será efetuada da mesma maneira que a colisão entre princípios. Embora os direitos fundamentais não sejam tecnicamente equivalentes aos princípios constitucionais, aqueles visam a promover os valores da autonomia e da liberdade na ordem jurídica e, especialmente, do princípio da dignidade da pessoa humana.

$\mathrm{Na}$ aparente colisão entre princípios constitucionais, a lesão aos princípios deverá ser minimizada, a fim de garantir a existência principiológica mútua no ordenamento jurídico; apenas a aplicabilidade de um determinado princípio poderá ser afastada mediante o caso concreto, mas a sua existência jamais poderá ser anulada. Da mesma maneira, deverão ser solucionados os aparentes conflitos entre direitos fundamentais.

4 Enunciado n. 405 do Conselho de Justiça Federal: As informações genéticas são parte da vida privada, e não podem ser utilizadas para fins diversos daqueles que motivaram seu armazenamento, registro ou uso, salvo com autorização do titular. 
Nesse diapasão, pondera Pereira Filho (2012, p.1717), que "não significa serem os direitos fundamentais sempre princípios, e sim que dos direitos fundamentais se podem inferir princípios, o que é coisa completamente diferente."

Os princípios são valores historicamente determinantes à construção da sociedade e possuem aplicabilidade imediata em variados fatos e situações. 0 grau de abstração elevado dos princípios não permite que a solução de conflitos seja adotada da mesma forma que uma mera antinomia normativa, cuja solução se dá através dos critérios da especialidade, hierarquia ou antiguidade, de forma que uma lei excluirá a outra.

Com efeito, elucida Alexy (2008, p.94) que "conflitos entre regras ocorrem na dimensão da validade, enquanto as colisões entre princípios - visto que só princípios válidos podem colidir - ocorrem para além dessa dimensão, na dimensão do peso."

Aduz Barroso et al $(2008$, p.55) aponta que a ponderação é uma técnica de decisão própria para os denominados hard cases, nos quais a utilização da subsunção é vedada, em virtude do princípio da unicidade, que preceitua que as disposições constitucionais possuem a mesma hierarquia e necessitam de uma interpretação harmônica. Nesses casos, verifica-se a existência de premissas maiores igualmente válidas e de idêntica hierarquia, que apontam para soluções normativas distintas, e, em determinados casos, contraditórias.

Na colisão entre princípios, Alexy (2008, p. 92) preconiza que um deles deverá ser o princípio cedente, o que não implica invalidade do aludido princípio ou que nele deverá ser inserida uma determinada cláusula de exceção, mas sim que um dos princípios, mediante a existência de condições específicas, terá precedência com relação ao outro.

Barroso et al (2008, p. 56) expõe que a ponderação costumava ser utilizada em casos, nos quais dois princípios de mesma hierarquia entravam em aparente conflito, isto é, a ponderação encontrava-se intimamente ligada à teoria dos princípios. Gradativamente, a ponderação tornou-se uma técnica de decisão jurídica autônoma, aplicável a outras situações que não o conflito de princípios.

Através da ponderação, os conflitos normativos podem ser solucionados de forma menos gravosa, possibilitando a existência de ambas as normas em oposição, sem a exclusão de qualquer uma delas, ainda que, no caso concreto, as normas possam ser aplicadas em intensidades distintas ou uma delas terá sua aplicabilidade afastada diante do caso concreto (BARROSO et al, 2008, p. 57).

A solução apresentada deverá observar as peculiaridades que revestem a situação sob a ótica da dignidade da pessoa humana, ou seja, mediante o caso concreto, deverá ser adotado o direito que proporcione maior adequação aos ditames do princípio da dignidade da pessoa humana, sem a invenção de novos direitos com aplicação retroativa (DWORKIN, p. 127).

Nesse sentido, Sarlet (2010, p. 311) assevera que o macroprincípio da dignidade da pessoa apenas será plenamente observado, se houver possibilidade de uma existência que permita a fruição e gozo dos direitos fundamentais, para que seja possibilitado o pleno desenvolvimento da personalidade.

Segundo Vargas (apud Scalquette), na colisão entre o direito à intimidade e o direito de conhecimento da origem genética, deverá prevalecer o direito do filho em conhecer sua origem genética. 


\begin{abstract}
O conhecimento da origem biológica - saber quem é seu pai ou mãe biológica - é de grande importância, tanto para a própria identidade da pessoa, como para o desenvolvimento de sua personalidade. É um direito que tem todo o indivíduo pelo simples fato de nascer e, por sua vez, é parte dos direitos fundamentais amparados pela Constituição. Sob outro ponto de vista, o direito do doador à sua intimidade ou o direito dos pais a não ter a interferência de um terceiro na relação com o filho não podem justificar o anonimato do doador. Ao existir uma colisão de direitos entre os direitos do filho e os do doador ou do casal receptor, deve prevalecer o direito do filho, não só por ser a parte mais frágil da relação, mas sim porque seus direitos são fundamentais para o desenvolvimento da criança. (VARGAS apud SCALQUETTE, 2010, p. 232).
\end{abstract}

Lôbo (2004, p. 525) pondera que o direito ao conhecimento da origem genética é tutelado pelo princípio da dignidade da pessoa humana, sendo um direito personalíssimo, irrenunciável e imprescritível, garantido à pessoa por se tratar de um direito fundamental, na forma de direito da personalidade.

Almeida (2004, p.429) aduz que o direito do filho existe em relação ao "direito natural da individualidade e da diversidade, que servem como fundamento para outro direito, o da identificação - pessoal (eu comigo) e social (eu com outros)."

Mediante cautelosa ponderação a depender do caso concreto, o direito à origem genética passa a ser, hipoteticamente, o direito fundamental que mais corresponderá aos ditames do princípio da dignidade da pessoa humana (CABRAL; CAMARDA, 2013).

Em situações nas quais o indivíduo venha a conhecer efetivamente sua origem genética, por força de proteção constitucional, advém o questionamento do limite da relativização do direito à intimidade genética do doador, bem como se há possibilidade de alteração no estado de filiação previamente constituído.

0 conhecimento da origem genética possui finalidade completamente distinta de uma investigação de paternidade comum, que constitui estado de filiação e implica em alteração de registro civil e obrigações de cunho patrimonial, isto é, a identidade genética é um direito da personalidade que não se relaciona com obrigações inerentes ao Direito das Famílias (LÔBO, 2004, p.525).

Dessa forma, o conhecimento da origem genética não possui como atribuição possibilitar a criação de um novo estado de filiação entre a criança e o doador, tendo em vista que o estado de filiação socioafetiva previamente constituído entre a criança e o pai socioafetivo é irrevogável. ${ }^{5}$

Com efeito, o vínculo de parentesco civil estabelecido entre a criança e o pai socioafetivo certamente não será rompido, pois a "função de pai não se confunde com a de ascendente biológico" (ENEIAS; ALVES, 2009).

Decerto, segundo Diniz (2011, p.626), caso fosse atribuído novo estado de filiação com o doador de material genético, a criança passaria a ter dois pais registrais, o que geraria, sem dúvida, uma paternidade incerta.

\title{
5 CONCLUSÃO
}

A crescente utilização da reprodução assistida heteróloga traz benefícios ao proporcionar maior eficácia ao exercício dos direitos reprodutivos e possibilitar maior abrangência ao conceito de paren-

5 Enunciado $n^{0} 111$ do Conselho de Justiça Federal: A adoção e a reprodução assistida heteróloga atribuem a condição de filho ao adotado e à criança resultante de técnica conceptiva heteróloga; porém, enquanto na adoção haverá o desligamento dos vínculos entre o adotado e seus parentes consanguíneos, na reprodução assistida heteróloga sequer será estabelecido o vínculo de parentesco entre a criança e o doador do material fecundante. 
tesco civil, mas, por outro lado, também proporciona inúmeros questionamentos, no que concerne à escassa regulamentação normativa no Brasil.

No século XX, era praticamente inconcebível a noção de que o vínculo biológico poderia ser preterido em relação ao vínculo socioafetivo, como ocorre nas técnicas de reprodução assistida heteróloga, nas quais o doador de material genético, apesar de possuir vínculo biológico com a criança, atuará como um mero agente auxiliador, ao passo que o marido ou convivente que expressou seu consentimento em relação ao emprego da referida técnica será considerado pai da criança para todos os efeitos civis.

Apesar da inovação trazida pelo Código Civil de 2002, através da inserção da cláusula geral "outra origem", expressa pelo artigo 1.593 do referido diploma legal, que mitigou a visão essencialmente ligada à existência de vínculo biológico, presente no Código Civil de 1916, questões relacionadas aos beneficiários da reprodução assistida, bem como a extensão do sigilo do doador de material genético e o direito ao conhecimento da origem genética não poderão permanecer isentos de apreciação pelo legislador.

A despeito da instauração de insegurança jurídica com relação aos reais limites do emprego das técnicas de reprodução assistida heteróloga, a lacuna legislativa não pode servir como obstáculo à satisfação dos direitos dos envolvidos. A atuação do poder judiciário deverá estar pautada nos limites da razoabilidade e proporcionalidade, a fim de que não sejam impostas obrigações descabidas ao doador de material genético, e que o indivíduo oriundo do emprego de técnica de reprodução assistida não seja privado injustamente do conhecimento de suas origens.

É possível concluir que, enquanto não surgir adequada regulamentação normativa no país a respeito do emprego das técnicas de reprodução assistida, a proteção principiológica constitucional e infraconstitucional deve ser respeitada, em especial, o princípio da dignidade da pessoa humana, de forma a impor limites ao avanço científico trazido pela reprodução assistida e a proporcionar maior eficácia ao exercício dos direitos reprodutivos. 


\section{REFERÊNCIAS}

ALEXY, Robert. Teoria dos direitos fundamentais. Tradução de Virgílio Afonso da Silva. São Paulo: Malheiros, 2008.

ALMEIDA, Maria Christina de Almeida. 0 direito à filiação integral à luz da dignidade humana. Anais do IV Congresso de Direito de Família. Belo Horizonte: DelRey, p.417-435, 2004.

BARROSO, Luiz Roberto et al. A nova interpretação constitucional: ponderação, direitos fundamentais e relações provadas. 3. ed. Rio de Janeiro: Renovar, 2008.

CABRAL, Hildeliza Lacerda Tinoco Boechat; CAMARDA, Dayane Ferreira. Intimidade Versus Origem Genética: A ponderação de interesses aplicada à Reprodução Assistida Heteróloga. Disponível em: <www.antigompmg.mp.br/portal/public/interno/arquivo/id/324>. Acesso em: 01 set. 2016.

COSTA, Judith Hofmeister Martins. O Direito privado como um sistema em construção: as cláusulas gerais no projeto do Código Civil Brasileiro. Revista de Informação Legislativa, v.35, n.139, p.5-22, jul/set.1998.

DIAS, Maria Berenice. Manual de direito das famílias. 10. ed. São Paulo: Revista dos Tribunais. 2015.

DINIZ, Maria Helena. 0 estado atual do biodireito. 3. ed. São Paulo: Saraiva. 2011.

DWORKIN, Ronald. Levando os direitos a sério. Tradução de Nelson Boeira. 1.ed. São Paulo: Martins Fontes. 2002.

ENEIAS, Miriam Soares; SILVA. Priscilla Alves. Inseminação artificial heteróloga: 0 reconhecimento da origem genética à luz do princípio da dignidade da pessoa humana. Disponível em: $<$ http://unipacaraguari. edu.br/oPatriarca/V3arquivos/trabalhos/artigo03miria . pdf > Acesso em: 28 ago. 2016.

FARIAS,CristianoChaves de;ROSENVALD,Nelson. CursodeDireito Civil. Volume6:Familias. 5. ed. Salvador.Juspodivm, 2013.

FERREIRA FILHO, Manoel Gonçalves. Curso de direito constitucional. 38. ed. São Paulo: Saraiva. 2012.

GAMA, Guilherme Calmon Nogueira da. Efeitos Civis da Reprodução Assistida Heteróloga. Anais do IV Congresso de Direito de Família. Belo Horizonte: DelRey, p.265-305.

GLANCY, Dorothy J. The invention of right to privacy. n. 21 Ariz. L. Rev. 1. 1979.

GONÇALVES, Carlos Roberto. Direito civil brasileiro, volume 6. 3. ed. São Paulo: Saraiva, 2011.

LOCATELI, Claudia Cinara; PANDOLFO, Ana Cristina. A intimidade genética: direito à intimidade eà informação na proteção dos dados genéticos. Revista do CEJUR/TJSC: Prestação Jurisdicional, v. 1, n. 02, p. 92 - 119, out. 2014.

LÔBO, Paulo Luiz Netto. Direito ao estado de filiação e direito à origem genética: uma distinção necessária. Anais do IV Congresso de Direito de Família. Belo Horizonte: DelRey, p.505-531, 2004.

SARLET, Ingo Wolfgang. 0 princípio da dignidade da pessoa humana e os direitos fundamentais. 10. ed. Porto Alegre: Livraria do Advogado, 2010.

SCALQUETTE, Ana Cláudia S. Estatuto da reprodução assistida. 1. ed. São Paulo: Saraiva, 2010.

VENOSA, Silvio de Salvo. Direito Civil. Direito de Família. Volume VI. 8. ed. São Paulo: Atlas, 2009. 